\title{
A relevância da observação na formação inicial docente com vistas no desenvolvimento da prática reflexiva
}

\section{The relevance of observation in teaching initial training with views in the development of reflective practice}

\author{
Denise Santos de Souza (dedessza@gmail.com) \\ Universidade Luterana do Brasil (PPGECIM - ULBRA) \\ Cristine Santos de Souza da Silva (cristine3s@ hotmail.com) \\ Universidade Luterana do Brasil (PPGECIM - ULBRA) \\ Everton Bedin (bedin.everton@gmail.com) \\ Universidade Federal do Paraná (UFPR)
}

\begin{abstract}
Resumo:
A formação inicial docente é um dos alicerces da educação, uma vez que, é por meio dela, que ocorre a preparação profissional dos futuros professores, capacitando-os a desenvolver as habilidades fundamentais para sua prática. Dentre as principais competências para o ensino, se destaca a prática reflexiva, a qual possibilita que o professor avalie e aprimore a sua atuação junto aos estudantes. Neste contexto, tendo o enfoque a importância da prática da observação na formação inicial docente, o presente artigo objetivou analisar e discutir como se dá a prática reflexiva dos professores em sua atuação docente. A metodologia adotada, envolveu a observação das aulas de Química, em duas turmas distintas de $3^{\circ}$ ano do Ensino Médio, um no turno diurno e uma turno noturno, de uma escola da rede pública de ensino do município de Viamão/RS. Com resultado, observou-se que as turmas analisadas apresentaram realidades contrastantes, tanto no perfil dos alunos quanto na atuação profissional do professor. Ademais, verificou-se também, a importância da prática reflexiva e a necessidade de formação específica dos professores na área da Química, uma vez que, o conhecimento do conteúdo possibilita que os professores sejam mais efetivos na transposição didática.
\end{abstract}

Palavras-chave: Ensino de Química; Estágio Docente; Formação de professores; Prática reflexiva.

\begin{abstract}
:
Initial teacher training is one of the foundations of education, since it is through it that the professional preparation of future teachers occurs, empowering them to develop the fundamental skills for their practice. Among the main competencies for teaching, the reflexive practice stands out, which allows the teacher to evaluate and improve his/her performance with the students. In this context, focusing on the importance of the practice of observation in initial teacher education, this article aimed to analyze and discuss how the reflective practice of teachers takes place in their teaching practice. The methodology adopted involved the observation of chemistry classes in two distinct
\end{abstract}


classes of 3rd year of high school, one in the day shift and one night shift, of a public school in the municipality of Viamão/RS. As a result, it was observed that the analyzed classes presented contrasting realities, both in the profile of the students and in the professional performance of the teacher. In contrast, it was also verified the importance of reflexive practice and the need for specific training of teachers in the area of Chemistry, since the knowledge of the content allows teachers to be more effective in the didactic transposition.

Keywords: Chemistry teaching; Teaching Internship; Teacher training; Reflective practice.

\section{INTRODUÇÃO}

Considerando que a aquisição e a troca de conhecimentos alicerçam a educação, compete ao professor nortear os processos de ensino e aprendizagem dos alunos, é de suma importância que o professor esteja preparado para a prática docente, de modo a viabilizar e favorecer a compreensão dos estudantes acerca dos conteúdos trabalhados e dos objetivos traçados.

No que tange a formação docente, tendo em vista as inúmeras competências que o professor precisa adquirir para desenvolver o processo de ensino, percebe-se que esta é uma etapa primordial em sua formação profissional, pois é um momento em que o professor se torna capaz de aprimorar a própria prática e qualificar a própria ação. Ademais, tendo como base a preparação do cidadão e o futuro profissional docente, todas as áreas estão de alguma forma subordinadas à educação e, consequentemente, a atuação dos professores (PERRENOUD, 2000).

Durante a formação inicial de professores são realizados os estágios de observação, os quais buscam a inserção dos graduandos na realidade das escolas, assim como a reflexão acerca das mais diversas situações vivenciadas. Portanto, espera-se que quando inseridos no contexto escolar, os graduandos possam adquirir uma visão realística do sistema educacional, a qual é essencial para a prática docente (FREIRE, 1996; HAGEMEYER, 2004). Diante disso, este artigo tem por objetivo apresentar algumas considerações acerca das observações realizadas durante as aulas de Química do $3^{\circ}$ ano em duas turmas do Ensino Médio, de turnos distintos, buscando averiguação do perfil e da prática reflexiva do professor titular. 


\section{O PAPEL DO DOCENTE}

Segundo Giugno (2004) a qualificação e o preparo dos estudantes para a compreensão do mundo ocorrem por meio da transmissão dos significados das teorias da ciência e, posteriormente, da construção do conhecimento. Desta forma, cabe ao professor fazer do ensino, uma linguagem que favoreça o entendimento do mundo aos alunos, oferecendo a oportunidade de pensar sobre questões diversificadas, sob diferentes olhares e, assim, aprender a estabelecer relações não lineares com os objetos do conhecimento, dando-lhes significado (CHASSOT, 2016a; 2004; MALDANER; ZANON, 2010; PEREIRA; AZEVEDO, 2012).

Dessa forma, o professor precisa executar suas atividades de maneira continente, de modo a adotar estratégias que possibilitem que os conteúdos trabalhados em sala de aula sejam assimilados, suportados e compreendidos pelos alunos. Portanto, é necessário que os professores tomem para si a tarefa de facilitar, potencializar e conduzir a aquisição do conhecimento escolar (GIUGNO, 2004; MACHADO, 2014; PERAZZOLO; STECANELA, 2012; SMITH; STRICK, 2012).

Nesta perspectiva, tem-se que a prática docente é relevante para que os processos de ensino e aprendizagem ocorram com eficiência, pois é o professor quem tem a função de aproximar os conteúdos dos alunos e apresentá-los em suas múltiplas formas cotidianas. Além disso, é a partir das relações entre os alunos, os professores e os demais segmentos da comunidade escolar, que o sujeito viverá, na prática, o conceito de cidadania (ZATTERA, 2004).

Estudos apontam que muitos são os fatores que interferem na prática docente, tais como o condicionamento dos professores por um sistema e a infraestrutura escolar, que por vezes acabam por influenciar na formação dos alunos. Entretanto, o aprimoramento do ensino depende do professor e, consequentemente, de seu interesse, de seu conhecimento e de sua disposição para trabalhar os conteúdos adequadamente (URATA; DA SILVEIRA, 2011).

Outrossim, é necessário considerar a forma com a qual o trabalho escolar é estruturado, pois incumbe ao professor uma elevada carga horária, o que dificulta a 
organização dos próprios afazeres no ambiente em que se realiza, além de turmas com um número excessivo de alunos e o controle pedagógico que restringe a liberdade de ação docente, visto que o professor saturado não consegue planejar, avaliar ou modificar suas aulas (CHASSOT, 2016b; DE QUADROS et al., 2011; TREVISAN; MARTINS, 2006).

\section{A FORMAÇÃO INICIAL DOCENTE E O ENSINO DE QUÍMICA}

A formação inicial docente se fundamenta na formação básica dos professores com vistas na sua futura prática docente, tendo por finalidade a preparação de profissionais cujas habilidades estejam de acordo com a necessidade da sociedade. Conforme as suas atribuições, o professor é um dos agentes da preparação dos alunos para o exercício da cidadania, a qual ocorre por meio da aquisição de conhecimentos que fundamentam os processos decisórios (PASQUARELLI; OLIVEIRA, 2017).

Entretanto, de acordo com Shulman (2014), para que o professor potencialize a compreensão do conteúdo pelos alunos, este necessita ter a sua base de conhecimentos desenvolvida. Assim, tendo como gênese a prática docente, o autor relacionou quais são os conhecimentos necessários para a efetiva prática docente, a saber: (i) o conhecimento do conteúdo; (ii) o conhecimento pedagógico geral; (iii) o conhecimento do currículo; (iv) o conhecimento pedagógico do conteúdo; (v) o conhecimento dos alunos e de suas características; (vi) o conhecimento do contexto educacional; e (vii) o conhecimento dos fins, propósitos e valores da educação.

Neste contexto, é possível perceber a importância dos estágios no percurso acadêmico, uma vez que os conhecimentos dos alunos e de suas características, assim como o conhecimento do contexto educacional e o conhecimento pedagógico do conteúdo, serão desenvolvidos e aprimorados quando da introdução dos graduandos na realidade educacional. Logo, no tocante da formação docente e do Ensino de Química, é crucial que os professores, além da formação específica na área, a qual fundamenta os conhecimentos de conteúdo, tenham consciência da importância da disciplina a ser ministrada, e que por meio da sua prática tornem a Química atrativa e compreensível 
aos alunos. Outrossim, o professor transmissor de conteúdos precisa se tornar um professor formador (CHASSOT, 2014; TREVISAN; MARTINS, 2006).

A formação docente precisa capacitar os professores à reflexão acerca de suas ações, pois a capacidade reflexiva é inata e o seu desenvolvimento precisa de favorecimentos, tais como contextos que envolvam liberdade e responsabilidade (ALARCÃO, 2011). Em outras palavras, deseja-se que:

[...] os professores sejam seres pensantes, intelectuais, capazes de gerir a sua ação profissional. Queremos também que a escola se questione a si própria, como motor do seu desenvolvimento institucional. Na escola, e nos professores, a constante atitude de reflexão manterá presente a importante questão da função que os professores e a escola desempenham na sociedade e ajudará a equacionar e resolver dilemas e problemas. (ALARCÃO, 2011, p. $50)$.

Portanto, para que haja um aprimoramento da prática docente e uma aquisição de novos conhecimentos voltados para aprendizagem significativa dos estudantes durante a formação docente, é necessário que os professores sejam instigados a refletir sobre as suas ações, buscando melhorias constantes para a qualificação da prática pedagógica. Ademais, enfatiza- se a afirmação de Carvalho e Andrade (2019, p.400) que "A formação docente é um processo contínuo, desde a formação inicial até a formação continuada que se estende durante os anos de profissão."

\section{METODOLOGIA}

Tendo como base o objetivo traçado, a aquisição dos dados apresentados neste artigo ocorreu por meio da análise das observações realizadas nas aulas do componente curricular de Química, em duas turmas de $3^{\circ}$ ano do Ensino Médio, de uma escola da rede pública estadual situada no município de Viamão/RS, no decorrer do segundo semestre do ano de 2019. Foram observadas 16 horas/aula, sendo 8 horas/aula em uma turma do período diurno e 8 horas/aula em uma turma do período noturno. Em virtude das observações terem ocorrido em dois turnos, foram acompanhadas as aulas de professores distintos, os quais são identificados nessa pesquisa como professores $\mathrm{A}$ 
(diurno) e B (noturno). Todas as observações foram anotadas em um diário de bordo, que segundo Zabalza (1994), são instrumentos que implicam a reflexão.

Além disso, foi realizada uma entrevista com os professores, previamente a prática da observação. Segundo Duarte (2004) destaca, as entrevistas são fundamentais quando se deseja mapear atitudes, práticas, crenças e valores de universos sociais específicos. Além disso, as entrevistas, de acordo com Zabalza (1994), complementam as observações, uma vez que as narrativas possibilitam a compreensão e a análise das ações com base em diferentes perspectivas.

\section{RESULTADOS E DISCUSSÃO}

Conforme mencionado na metodologia, as observações ocorreram em duas turmas, ambas do $3^{\circ}$ ano do Ensino Médio, que apresentaram professores distintos. Em relação às turmas, a do período diurno era composta por 24 alunos, os quais em sua maioria realizavam estágio remunerado ou trabalhavam meio turno, apresentando um pequeno número de repetentes e possuindo uma frequência elevada de alunos. Quanto à turma do período noturno, era composta por 32 alunos, os quais em sua maioria trabalhavam turno integral, continha um elevado número de repetentes e a frequência dos alunos nas aulas era muito baixa. Esta constatação está de acordo com o verificado por Souza (2016) em sua pesquisa, onde foi averiguado que os estudantes do turno noturno tendem a apresentar maiores índices de reprovação e de evasão que os alunos matriculados no diurno. Com base nos dados obtidos, foi traçado um perfil de características de cada professor, conforme apresentado na Tabela 1.

Tabela 1 - Características dos professores observados.

\begin{tabular}{|c|c|c|}
\hline Característica & Professor A & Professor B \\
\hline Idade & 32 anos & 34 anos \\
\hline $\begin{array}{l}\text { Formação } \\
\text { Acadêmica }\end{array}$ & $\begin{array}{l}\text { Biologia. Atualmente está cursando a segunda } \\
\text { graduação em Química. }\end{array}$ & Matemática \\
\hline Tempo de docência & 10 anos & 12 anos \\
\hline Atuação profissional & $\begin{array}{l}\text { - Atua nos três anos do Ensino Médio na rede } \\
\text { estadual, lecionando as disciplinas de } \\
\text { Química e Biologia. } \\
\text { - Atua na rede municipal de ensino no Ensino } \\
\text { Fundamental, lecionando a disciplina de } \\
\text { Ciências do } 6^{\circ} \text { ao } 9^{\circ} \text { ano. }\end{array}$ & $\begin{array}{l}\text { - Atua nos três anos do Ensino Médio na rede } \\
\text { estadual, lecionando as disciplinas de } \\
\text { Química, Matemática e Física. } \\
\text { - Atua na rede municipal de ensino no Ensino } \\
\text { Fundamental, lecionando a disciplina de } \\
\text { Matemática do } 6^{\circ} \text { ao } 9^{\circ} \text { ano. }\end{array}$ \\
\hline Vínculo Profissional & Temporário & Temporário \\
\hline Formação & Acha importante e sempre que possível faz. & Não acha importante, faz somente quando lhe \\
\hline
\end{tabular}




\begin{tabular}{|l|l|l|}
\hline continuada & $\begin{array}{l}\text { Participa da equipe de projetos de pesquisa da } \\
\text { escola. }\end{array}$ & é exigido. \\
\hline $\begin{array}{l}\text { Perspectivas acerca } \\
\text { do futuro na } \\
\text { docência }\end{array}$ & $\begin{array}{l}\text { Almeja fazer concursos para se tornar efetivo } \\
\text { na rede. Objetiva concluir a segunda } \\
\text { graduação em Química e atuar somente no } \\
\text { Ensino Médio. }\end{array}$ & $\begin{array}{l}\text { Almeja fazer concursos para se tornar efetiva } \\
\text { na rede. Não pretende fazer outra graduação } \\
\text { ou especialização. }\end{array}$ \\
\hline $\begin{array}{l}\text { Trabalha com aulas expositivas, } \\
\text { utilizadas }\end{array}$ & $\begin{array}{l}\text { demonstrativas, experimentais, pesquisas, } \\
\text { entre outros. }\end{array}$ & Trabalha com aulas expositivas. \\
\hline $\begin{array}{l}\text { Material de apoio } \\
\text { utilizado }\end{array}$ & $\begin{array}{l}\text { Livro didático, laboratório de ciências, sala de } \\
\text { multimídia, entre outros. }\end{array}$ & Livro didático. \\
\hline Métodos avaliativos & $\begin{array}{l}\text { Provas, trabalhos realizados em casa e em } \\
\text { aula, projetos de pesquisa, atividades } \\
\text { experimentais, entre outros. }\end{array}$ & Provas \\
\hline $\begin{array}{l}\text { Costuma passar atividades para os alunos } \\
\text { fazerem em casa. } \\
\text { Costuma revisar os conteúdos trabalhados em } \\
\text { aulas anteriores e corrigir as tarefas de casa } \\
\text { no início das aulas. }\end{array}$ & $\begin{array}{l}\text { Não costuma passar atividades para os alunos } \\
\text { fazerem em casa. }\end{array}$ \\
\hline conteúdos & solicitado pelos alunos.
\end{tabular}

Fonte: Os autores (2020)

Como pode-se perceber, ambos os professores apesar de jovens, possuem bastante tempo de docência, tendo iniciado a prática docente antes mesmo da conclusão da graduação. Quanto ao perfil de características e atitudes dos professores A e B em relação à docência, conforme apresentado na Tabela 1, é possível perceber que possuem estilos de docência distintos. À vista disso, e com ênfase na observação, é plausível admitir que o Professor A apresentou mais ações e comportamentos pertinentes à prática reflexiva do que o Professor $\mathrm{B}$, o qual, em meio as suas colocações, demonstrou não possuir um perfil de professor reflexivo.

O Professor A tem sua formação inicial em Biologia, e atualmente leciona as disciplinas de Biologia e de Química nos três anos do Ensino Médio, e também, concomitantemente, leciona a disciplina de Ciências do $6^{\circ}$ ao $9^{\circ}$ ano no Ensino Fundamental. Diante do fato de o professor lecionar mais de uma disciplina para as turmas do Ensino Médio, foi possível perceber, durante as observações, que por vezes, nas aulas de Química, ele abordava pormenores acerca da disciplina de Biologia. Entretanto, tais assuntos não se relacionavam com o conteúdo da disciplina de Química. Embora se percebesse que o professor julgava estar buscando uma forma interdisciplinar de trabalho, era notório que se tratava de uma ação em decorrência do professor ter mais conhecimentos na área da Biologia. Essa ação, de certa forma, provoca um declínio na ação docente e no próprio fazer educação, pois o professor, enquanto coordenador do ambiente de ensino, precisa refletir sobre aquilo que é viável e 
tangível à aprendizagem do aluno naquele espaço-tempo, buscando aperfeiçoar-se em relação ao conteúdo, mesmo que este conteúdo esteja fora da sua zona de conforto.

No que tange a formação docente, torna-se relevante que o professor tenha a formação específica à área de atuação, uma vez que o conhecimento do conteúdo é inerente aos processos de ensino e aprendizagem. De acordo com Schulman (2014, p. 208):

\begin{abstract}
O professor tem responsabilidades especiais com relação ao conhecimento do conteúdo, pois serve como fonte primária da compreensão deste pelo aluno. A maneira como essa compreensão é comunicada transmite aos alunos o que é essencial e o que é periférico na matéria. Diante da diversidade dos alunos, o professor deve ter uma compreensão flexível e multifacetada, adequada à oferta de explicações diferentes dos mesmos conceitos ou princípios. Conscientemente ou não, o professor também transmite ideias sobre como a "verdade" é determinada numa área e um conjunto de atitudes e valores que influenciam notoriamente a compreensão do aluno. Essa responsabilidade demanda especialmente a profundidade de compreensão do professor das estruturas da matéria, assim como suas atitudes e entusiasmo com relação ao que está sendo ensinado e aprendido. Esses vários aspectos do conhecimento do conteúdo, portanto, são devidamente entendidos como uma característica central da base de conhecimento para o ensino.
\end{abstract}

Assim, quando o professor A começou a lecionar a disciplina de Química, sentiu a necessidade de aprofundar e aprimorar os seus conhecimentos, sentindo-se motivado a buscar uma formação continuada por meio de uma segunda graduação em Química, a qual está em andamento. Esta atitude está associada à prática reflexiva, permitindo ao professor identificar os seus pontos a serem melhorados e, assim, buscar por estratégias que venham aprimorar a sua ação docente (ALARCÃO, 2011).

Além disso, o professor A afirmou buscar e valorizar a formação continuada, assim como participar da equipe de projetos de pesquisa da escola. Com base nisso, pode-se perceber que o professor compreende que, assim como o afirmado por Freire (1996), os processos de aprendizagem devem ser constantes. Destaca-se que como um ser inacabado que aprende e ensina, o professor precisa entender a essência do conceito de inacabamento e, em decorrência disso, compreender a necessidade de sua constante formação profissional (FREIRE, 1996).

Tendo como base as perspectivas futuras do Professor A, ele almeja ser efetivado na rede estadual de ensino, onde atualmente está atuando como professor temporário. 
Além de concluir a graduação em Química, ele pretende passar a atuar somente no Ensino Médio, por ser este o nível ao qual mais se identifica. A motivação do professor acerca da profissão é um dos aspectos centrais para a profissionalização docente, uma vez que quando motivado a tendência é que o professor permaneça estudando e atuando. Ademais, apesar dos baixos salários e desvalorização docente, a estabilidade profissional favorece a busca pela profissão (HAGEMEYER, 2004).

Em relação às metodologias adotadas pelo Professor A, este utiliza uma variedade de estratégias didáticas. Visando um maior envolvimento e aprendizado dos alunos, o professor não trabalha apenas com aulas expositivas; este fato é que merece destaque, pois diversos estudos acerca da aprendizagem em Química demonstram que o ensino baseado em aulas expositivas influencia na compreensão dos estudantes acerca do conteúdo, os quais acabam por desenvolver dificuldades de aprendizagem e, por vezes, aversão à disciplina (BEDIN, 2019; CHASSOT, 2014, 2016a; TRINDADE, 2010).

Assim como as metodologias, o professor A utiliza recursos didáticos variados em sua aula, uma vez que se trata de uma disciplina que necessita abstração e os conteúdos de Química por vezes não são fáceis de serem compreendidos. Com essa atitude, o professor demonstra preocupação em aprimorar a sua prática docente e potencializar a aprendizagem dos alunos. De acordo com Bedin (2019, p. 102), sabe-se que "o trabalho do professor de química não deve se limitar a transmitir conteúdos e significados de símbolos e fórmulas, mas favorecer as atividades psico-cognitivas dos estudantes".

Nesta perspectiva, tem-se que muitos são os saberes e os conhecimentos desenvolvidos pelos professores ao longo de sua formação e prática educativa, os quais capacitam e aprimoram a própria ação docente. Entretanto, é necessário que o professor reflita sobre a sua prática e busque aprimorar as suas aulas (ALARCÃO, 2011; TARDIF, 2002), pois se esta implementação "for planejada em relação ao aluno, pode propiciar um conjunto de práticas preestabelecidas que têm o propósito de contribuir para que este se aproprie de conteúdos sociais e culturais de maneira crítica e construtiva" (BEDIN, 2019, p. 103).

Em decorrência da variedade de metodologias adotadas pelo professor, os instrumentos avaliativos também são diversificados. Assim, as avaliações dos 
estudantes ocorrem por meio de provas, trabalhos, pesquisas, atividades experimentais, entre outros. Não restringir o processo avaliativo a aplicações de provas é essencial à aprendizagem dos alunos. A utilização exclusiva de provas favorece a aprendizagem mecânica, a qual se fundamenta na memorização. Em contraponto, avaliações diferentes possibilitam que o professor explore os pontos fortes dos alunos e os envolva em seus processos de aprendizagem. Assim, tem-se um professor, para além de um transmissor de conhecimento, que forma sujeitos capazes de pensar, tomar decisões e buscar por informações. Assim, o professor se transforma em um mediador dos processos de aprendizagem e não a única fonte de conhecimento dos alunos (CHASSOT, 2007; LIMA, 2012).

Considerando o desenvolvimento das aulas, observou-se que os alunos participam em sua maioria ativamente das atividades propostas pelo professor e que, apesar da utilização de metodologias diversificadas pelo docente, os alunos apresentam dificuldades de entendimento em relação aos conteúdos. Em virtude disto, o professor constantemente passa para os alunos atividades extraclasse, revisa os conteúdos dados no início das aulas e corrige as atividades com os alunos.

Em relação às dificuldades de aprendizagem em Química, estudos realizados já constataram que, devido a Química ser uma disciplina das ciências exatas e trabalhar com muitas fórmulas, estruturas, nomenclaturas e conceitos abstratos, os alunos podem demonstrar bloqueios acerca do entendimento dos conteúdos, que podem refletir em baixo desempenho. Desta forma, é essencial que o professor identifique e busque sanar as dúvidas dos alunos durante o desenvolvimento dos processos de ensino e aprendizagem (SOUZA, 2018; DAMASCENO; DAMASCENO; DAMASCENO, 2015; SMITH; STRICK, 2012).

Já com relação ao Professor $B$, sua formação inicial é em Matemática e, atualmente, ele leciona as disciplinas de Matemática, Química e Física nos três anos do Ensino Médio, e concomitantemente, o professor também leciona a disciplina de Matemática do $6^{\circ}$ ao $9^{\circ}$ ano do Ensino Fundamental. Percebeu-se, durante as observações, que, ao contrário do Professor A, durante as aulas de Química não foram 
abordadas questões acerca das outras disciplinas; o professor se mostrou mais rígido acerca dos conteúdos específicos para cada disciplina em seus determinados períodos.

No tocante ao fato do professor ministrar disciplinas diferentes da sua formação inicial, isso ocorre normalmente em decorrência da necessidade de complementação de carga horária e da falta de professores formados em determinadas áreas, principalmente na rede pública. Essa prática pode influenciar na formação dos alunos, uma vez que o professor, quando não possui formação específica na área, não demonstra a ampliação do conhecimento do conteúdo necessário, assim como a interlocução com o conhecimento pedagógico do conteúdo; logo, tem-se um processo de aprendizagem insuficiente (SCHULMAN, 2014).

Em relação à formação continuada, o professor B afirma não achar importante, admitindo fazê-la somente quando lhe é exigido. Esta afirmação é preocupante e vai ao desencontro do que afirmam autores como Alarcão (2011) e Tardif (2002), que defendem que o professor, assim como os profissionais das mais diversas áreas, precisa estar em constante formação, visando principalmente o aprimoramento da prática docente. Ademais, tendo como base a ação reflexiva, se percebe que o professor não é propenso a rever a sua prática, uma vez que acredita estar completamente preparado para a docência, não necessitando de quaisquer outras formações.

Considerando as perspectivas futuras, o Professor B também almeja ser efetivado na rede estadual de ensino, uma vez que está atuando como professor temporário. Em decorrência da crescente falta de profissionais docentes, os contratos temporários têm sido a alternativa mais utilizada por diversos estados brasileiros. Entretanto, esta estrutura segundo Pereira (2018, p. 60) é desfavorável aos profissionais devido "a perda de direitos dos trabalhadores, a impossibilidade de progressão na carreira e de modo geral, a precarização do trabalho". Sendo assim, a falta de estabilidade e a perspectiva profissional são elementos desmotivadores, podendo estar relacionados à falta de interesse do professor pela formação continuada. Ainda, destaca-se que o Professor B, apesar de ministrar disciplinas às quais não possui formação, não pretende fazer outra graduação, tampouco uma especialização. 
No tocante as metodologias utilizadas pelo Professor B, este se restringe à utilização de aulas expositivas. Esta falta de flexibilidade das metodologias adotadas pode estar relacionada à falta de conhecimento do conteúdo da disciplina, pois, conforme Cardoso, Del Pino e Dorneles (2012), Schulman (2014) e Tardif (2002), que investigam sobre os saberes docentes, para que o professor se aproprie da utilização de metodologias didáticas variadas em sua prática docente é necessário que haja o domínio dos conteúdos trabalhados. Além disso, Cardoso, Del Pino e Dorneles (2012, p. 7) salientam que "para ensinar algo a alguém é preciso entender, conhecer o assunto profundamente". Sendo assim, a formação específica na área de atuação essencial é relevante para que o aprimoramento do ensino e a qualificação do desenvolvimento dos conceitos e conteúdos ocorram de forma eficaz.

Durante as observações foi possível verificar que, em virtude da realização de aulas exclusivamente expositivas, o único material de apoio utilizado pelo Professor B foi o livro didático. Em virtude de o professor ministrar suas aulas do noturno, ele afirmou que os alunos, em razão de a maioria trabalhar tempo integral, não têm tempo de realizar trabalhos e/ou pesquisas em casa. Logo, o docente optou em seguir exclusivamente o uso do livro didático. Acerca da utilização do livro didático, Kato e Kiouranis (2013, p. 3) destacam que:

[...]a função principal do livro didático é dar suporte ao processo de ensinoaprendizagem. Para isso, é fundamental que o professor faça uso coerente desse material, considerando os pressupostos da educação química, de modo a possibilitar novos direcionamentos e abordagens da prática docente no processo de ensino-aprendizagem. Assim, os alunos poderão se apropriar dos conhecimentos e se tornar capazes de refletir criticamente sobre o meio em que estão inseridos.

Em decorrência da pouca variedade das metodologias adotadas e do uso excessivo do livro didático, pode-se verificar que o Professor B não apresenta um perfil de professor reflexivo, uma vez que para se enquadrar neste perfil o mesmo precisaria constantemente refletir acerca das suas ações, sendo essas passíveis de provocar modificações no sujeito, além de rever as suas metodologias e adotar novas estratégias de ensino, buscando romper com as velhas práticas e favorecer a aprendizagem (ALARCÃO, 2011). Portanto, assim como afirmado por Santos e Frizon (2013, p. 6), 
cabe a formação docente "[...] preparar os professores para que eles sejam reflexivos sobre suas ações, incansáveis pela busca de novos conhecimentos e práticas que melhorem seu desempenho em sala de aula e promova um aprendizado significativo aos alunos".

Em relação aos métodos avaliativos, o desempenho dos estudantes é medido exclusivamente por meio de provas, em geral estruturadas com questões objetivas, as quais são extraídas do livro didático. Segundo o Professor B, ele realiza provas objetivas em virtude das dificuldades de aprendizagem dos estudantes, os quais em geral são repetentes e não almejam dar continuidade nos estudos, uma que a formação no Ensino Médio é o maior objetivo destes alunos. Assim, por serem questões retiradas do livro didático, os estudantes conseguem se preparar mais para as avaliações, apresentando maior índice de aprovação na turma.

Apesar disto, em relação ao uso exclusivo de provas como sistema de avaliação, Santos e Frizon (2013, p.3) alertam que:

\begin{abstract}
Uma das possibilidades de o professor avaliar se seus alunos realmente aprenderam sobre algo é a maneira com que eles argumentam, conseguem estabelecer suas próprias conclusões e defende-las diante dos conceitos estudados. Avaliações baseadas em testes e provas, muitas vezes não são suficientes para avaliar o aprendizado do aluno, pois dependendo de como foi questionado o aluno poderá responder, colando, memorizando ou por um golpe de sorte principalmente nas questões de múltiplas escolhas.
\end{abstract}

Considerando o desenvolvimento das aulas do Professor B, observou-se que os alunos não participam ativamente das mesmas, apresentando, além de uma baixa frequência assídua, pouco entrosamento e interação entre os mesmos e estes com o professor, o qual após a explanação do conteúdo indica as páginas do livro e os exercícios a serem realizados. Destaca-se que a abordagem dos conteúdos ocorre de forma superficial, fato este que pode estar relacionado tanto à falta de formação do professor quanto às dificuldades de aprendizagem dos alunos relacionadas ao ensino de Química. Neste desenho, quando questionado acerca deste fato, o Professor B alegou que os alunos não conseguiriam acompanhar o conteúdo, caso a abordagem fosse mais aprofundada. 
Em decorrência do apresentado, percebe-se que apesar das diferenças entre os dois professores, ambos destacaram a dificuldade dos estudantes em compreender os conteúdos acerca da disciplina de Química não especificamente pela falta de dedicação ou interesse dos sujeitos, mas pelos conceitos e objetos de conhecimento, na visão destes, serem abstratos demais. Nesta linha, estudos têm sido realizados visando identificar e sanar as dificuldades dos estudantes, mas, em sua maioria, estas pesquisas defendem que a ação docente é a maior beneficiadora dos processos de ensino e aprendizagem. Ou seja, é a partir das mudanças e das estratégias diferenciadas adotadas pelos professores que estabelecem possibilidades aos estudantes compreenderem o ensino de Química e, consequentemente, gostarem da disciplina (DE QUADROS et al., 2011; SILVA; SOUZA, 2019; SOUZA, 2018).

Nesta perspectiva, percebe-se que ambos os professores analisados apresentam aspectos didáticos, metodológicos e de domínio dos conteúdos desenvolvidos passíveis de aprimoramento que diz respeito à disciplina de Química. Dessa forma, espera-se que o ensino desta ciência possa ser desenvolvido de forma contextualizada, partindo da realidade do aluno (macro) para a inserção dos conceitos e conteúdos relacionados à Química (micro). Afinal, de acordo com Finger e Bedin (2019, p. 12, 13):

[...] contextualizar no ensino de Química é uma forma de qualificar e aprimorar a aprendizagem, para que os alunos consigam relacionar os saberes da sociedade com os conteúdos científicos [...] para que, além de perceberem-nos em suas roupas, comidas e produtos do cotidiano em geral, consigam despertar interesse próprio pelo assunto para usufruir desses saberes e, de forma positiva, intervir no meio social em que se situam.

\section{CONSIDERAÇÕES FINAIS}

Conforme apresentado neste trabalho, a prática reflexiva na profissão docente favorece o aprimoramento profissional e a aquisição de novos conhecimentos. Nesta perspectiva, considerando a formação inicial, a realização dos estágios de observação proporciona ao graduando, por meio da inserção no contexto educacional, a vivência acerca da profissão e a interação com profissionais que já atuam na área. Esta ação é importante para que o futuro professor perceba que, assim como em outras profissões, existem diferentes perfis de professores, os quais são fundamentados nas características 
pessoais e nos valores de cada um. Entretanto, é crucial que o objetivo da educação seja o foco principal destes profissionais, os quais necessitam ser capazes de realizar uma autoavaliação e rever as suas ações por meio da reflexão.

Em especial na formação em Química, a ausência de profissionais na área se mostra um grande desafio, tendo como consequência a ação pedagógica de profissionais formados em outras áreas. Porém, para que os processos de ensino e aprendizagem sejam eficazes é necessário que o professor domine o conteúdo trabalhado, para avaliar, dentro do contexto social e cultural em que se encontra a escola.

O acompanhamento da prática de dois professores com estilos distintos de docência proporcionou uma reflexão acerca da docência, das competências necessárias para o aprimoramento do ensino e da realidade da educação pública brasileira. Sendo assim, essa pesquisa demonstrou que a importância dos estágios como momentos fundamentais na formação dos futuros professores, os quais passam a ter um entendimento acerca da profissão escolhida, projetando-se não mais na visão de aluno, mas como futuros professores.

Destarte, é necessário destacar que nas observações realizadas percebeu-se que ambos os professores se mostraram corajosos ao aceitarem ministrar uma disciplina a qual não possuem formação. O Professor A, no entanto, demonstrou ser mais reflexivo acerca da sua prática docente do que o Professor B. Vale lembrar, que esta pesquisa não teve o objetivo de realizar qualquer julgamento sobre a ação educativa dos dois professores, ou esquematizar algo que possa inferir o que é certo ou errado dentro da realidade em que a escola se insere, mas sim possibilitar o entendimento da relevância da prática reflexiva por meio dos estágios de observação. Sendo assim, conclui-se que quando o professor reflete sobre suas ações em sala de aula, ele tende a buscar e utilizar metodologias, recursos e materiais de apoio mais diversificados, vindo a contribuir com a aprendizagem dos alunos e a qualificação do ensino da disciplina que está em sua responsabilidade.

\section{REFERÊNCIAS}


ALARCÃO, I. Professores reflexivos em uma escola reflexiva. 8. ed. São Paulo: Cortez, 2011.

BEDIN, E. Filme, experiência e tecnologia no ensino de ciências química: uma sequência didática. Revista de Educação, Ciências e Matemática, v. 9, n. 1, 101-115, 2019.

BEDIN, E.; DEL PINO, J. C. Tecnologias no Ensino de Química: Uma Avaliação Neurocientífica para os Processos de Ensino e Aprendizagem. Revista Debates em Ensino de Química, v. 2, n. 1, p. 31-40, 2017.

CARDOSO, A. A.; DEL PINO, M. A. B.; DORNELES, C. L. Os saberes profissionais dos professores na perspectiva de Tardif e Gauthier: Contribuições para o campo de pesquisa sobre os saberes docentes no Brasil. In: IX ANPED SUL, Anais...Caxias do Sul, RS: 2012.

CARVALHO, E.; ANDRADE, M. Formação complementar de professores: análise de um curso de atividades por investigação. Revista Insignare Scientia - RIS, v. 2, n. 4, p. 396-415, 19 dez. 2019.

CHASSOT, A. Educação consciência. $2^{\circ}$ ed. Santa Cruz do Sul: Edunisc, 2007.

CHASSOT, A. Para que(m) é útil o ensino? 3º ed. Ijuí: Editora Unijuí, 2014.

CHASSOT, A. Alfabetização científica. $7^{\circ}$ ed. Ijuí: Editora Unijuí, 2016. a.

CHASSOT, A. Das disciplinas à indisciplina. $1^{\circ}$ ed. Curitiba: Editora Appris, 2016. b.

DAMASCENO, I.; DAMASCENO, M. J. P.; DAMASCENO, I. A. P. Aprendizagem significativa: reflexão para os atores educacionais com ênfase na disciplina de química. In: $8^{\circ}$ ENFOPE, Anais...Aracaju, SE: 2015.

DE QUADROS, A. L. et al. Ensinar e aprender Química: a percepção dos professores do Ensino Médio. Educar em Revista, n. 40, p. 159-176, 2011.

DUARTE, R. Entrevistas em pesquisas qualitativas. Educar, v. 24, p. 213-225, 2004.

FREIRE, P. Pedagogia da autonomia: saberes necessários à prática educativa. $25^{\circ}$ ed. São Paulo: Paz e Terra, 1996.

GIUGNO, J. L. D. P. Concepções socioistóricas: uma perspectiva para a redefinição das práticas educativas. In: DOTTI, C. M. (Ed.). Educação: as faces do novo. Caxias do Sul: EDUCS, 2004. p. 89-100.

HAGEMEYER, R. C. D. C. Dilemas e desafios da função docente na sociedade atual: os sentidos da mudança. Educar Curitiba, v. 24, n. UFPR, p. 67-85, 2004.

KATO, C. M.; KIOURANIS, N. M. M. O livro didático nas aulas de Química por estudantes do Ensino Médio. In: IX ENPEC, Anais...Águas de Lindóia, SP: 2013.

LIMA, J. O. G. De. Perspectivas de novas metodologias no Ensino de Química. Revista Espaço Acadêmico, v. 136, n. 1519-6186, p. 95-101, 2012.

MACHADO, A. H. Aula de química: discurso e conhecimento. $3^{\circ}$ ed. Ijuí: Editora Unijuí, 2014. 
MALDANER, O. A.; ZANON, L. B. Pesquisa educacional e produção de conhecimento do professor de química. In: SANTOS, W. L. P. dos; MALDANER, O. A. (Eds.). Ensino de Química em foco. Ijuí: Editora Unijuí, 2010. p. 368-378.

PASQUARELLI, B.; OLIVEIRA, T. B. de. Conceitos, procedimentos e atitudes na formação inicial : propostas para o ensino da cidadania. Ensino \& Pesquisa, v. 15, n. n.4, p. 158-177, 2017.

PERAZZOLO, O.; STECANELA, N. Aprendizagem como fenômeno relacional: perspectivas antropogênicas da função educativa. In: SOARES, E. M. S.; LUCHESE, T. A. (Eds.). Interlocuções na educação: história, filosofia e linguagens. Caxias do Sul: EDUCS, 2012. p. 65-82.

PEREIRA, L. D. S. Crise nas licenciaturas e a luta pela educação no Brasil. Uberlândia: Navegando Publicações, 2018.

PEREIRA, S.; AZEVEDO, T. M. De. Repetir ou transformar? uma análise dos "espaços de aprender" nas interações família-criança-escola. In: SOARES, E. M. do S.; LUCHESE, T. A. (Eds.). Interlocuções na educação: história, filosofia e linguagens. Caxias do Sul: EDUCS, 2012. p. 83-100.

PERRENOUD, P. Dez novas competências para ensinar. Porto Alegre: Artmed, 2000.

SANTOS, R. S.; FRIZON, M. D. Uma reflexão sobre a prática docente e o cotidiano escolar durante o estágio de Química. In: 33 EDEQ, Anais...Ijuí, RS: 2013

SCHULMAN, L. S. Conhecimento e ensino: fundamentos para a nova reforma. Cadernos Cenpec, [s. 1.], v. 4, n. n.2, p. 196-229, 2014.

SILVA, C. S. S.; SOUZA, D. S. As dificuldades de aprendizagem na perspectiva dos envolvidos no processo educacional. Revista de Estilos de Aprendizaje, v. 12, p. 5362, 2019.

SMITH, C.; STRICK, L. Dificuldades de aprendizagem de A a Z: um guia completo para pais e educadores. $1^{\circ}$ ed. São Paulo: Penso Editora Ltda, 2012.

SOUZA, D. S.. O reforço escolar como ferramenta auxiliar na aprendizagem da Química no Ensino Médio. 2018. 137 f. Dissertação (Mestrado em Ensino de Ciências e Matemática) Programa de Pós-Graduação em Ensino de Ciências e Matemática, Universidade Luterana do Brasil, Canoas, 2018.

SOUZA, E. M. De. A reprovação, evasão e abandono no ensino médio noturno de uma escola estadual do Amazonas. 2016. 140 f. Dissertação (Mestrado Mestrado Profissional em Gestão e Avaliação da Educação Pública) Faculdade de Educação, Universidade de Juiz de Fora, Juiz de Fora, 2016.

TARDIF, M. Saberes docentes e formação profissional. Rio de Janeiro: Vozes, 2002.

TREVISAN, T. S.; MARTINS, P. L. O. A prática pedagógica do professor de química: possibilidades e limites. UNIRevista, [s. 1.], v. 1, n. abril, p. 1-12, 2006.

TRINDADE, L. dos S. P. A alquimia dos processos de ensino e aprendizagem em química. São Paulo: Editora Madras, 2010. 
URATA, T. D. C.; DA SILVEIRA, H. E. Condicionantes da prática docente : relatos de uma professora de química da rede pública estatal Determinants of teaching practice: reports of a state public school teacher. In: VIII ENPEC, Anais...Campinas, SP:2011.

ZABALZA, M. A. Diários de aula: contributo para o estudo dos dilemas práticos dos professores. Porto: Porto Editora, 1994.

ZATTERA, M. N. Relações entre alunos e professores sob o olhar da pedagogia. In: DOTTI, C. M. (Ed.). Educação: as faces do novo. Caxias do Sul: EDUCS, 2004. p. $101-118$. 